\title{
Estimating building vulnerability to volcanic ash fall for insurance and other purposes
}

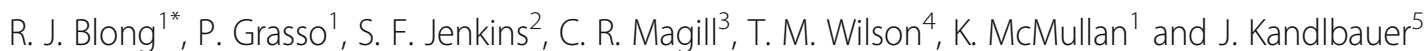

\begin{abstract}
Volcanic ash falls are one of the most widespread and frequent volcanic hazards, and are produced by all explosive volcanic eruptions. Ash falls are arguably the most disruptive volcanic hazard because of their ability to affect large areas and to impact a wide range of assets, even at relatively small thicknesses. From an insurance perspective, the most valuable insured assets are buildings. Ash fall vulnerability curves or functions, which relate the magnitude of ash fall to likely damage, are the most developed for buildings, although there have been important recent advances for agriculture and infrastructure. In this paper, we focus on existing vulnerability functions developed for volcanic ash fall impact on buildings, and apply them to a hypothetical building portfolio impacted by a modernday Tambora 1815 eruption scenario. We compare and contrast the different developed functions and discuss some of the issues surrounding estimation of potential building damage following a volcanic eruption. We found substantial variability in the different vulnerability estimates, which contribute to large uncertainties when estimating potential building damage and loss. Given the lack of detailed and published studies of building damage resulting from ash fall this is not surprising, although it also appears to be the case for other natural hazards for which there are far more empirical damage data. Notwithstanding the potential limitations of some empirical data in constraining vulnerability functions, efforts are required to improve our estimates of building damage under ash fall loading through the collection of damage data, experimental testing and perhaps theoretical failure analysis. For insurance purposes, the current building typologies provided for use with vulnerability functions are too detailed to map to the relatively limited information on building types that is typically available to insurers. Thus, efforts to provide vulnerability functions that can be used where only limited information is available regarding building types would also be valuable, both for insurers and for at-risk areas that have not been subject to detailed building vulnerability surveys.
\end{abstract}

Keywords: Tephra, Volcanic ash, Vulnerability functions, Fragility functions, Tambora 1815 eruption, Natural hazard losses

\section{Background}

This paper focuses on the vulnerability of buildings to tephra falls, summarising recent efforts to compare the existing approaches and estimates, and investigating how differing approaches could affect damage estimates. Tephra falls are formed when relatively fine-grained volcanic ash (particles $<2 \mathrm{~mm}$ ) and coarser lapilli (particles 2-64 $\mathrm{mm}$ ), produced during an explosive eruption are dispersed by winds away from the spreading umbrella region of a volcanic plume, falling out of suspension to form a deposit that can be less than millimetres to more

\footnotetext{
* Correspondence: russell.blong@aonbenfield.com

${ }^{1}$ Aon Benfield Asia-Pacific, Sydney, Australia

Full list of author information is available at the end of the article
}

than metres thick. Tephra falls, referred to colloquially, and throughout this paper, as ash falls, are one of the most widespread volcanic hazards (e.g. Magill and Blong, 2005). Although other hazards, such as pyroclastic density currents and lava flows, produce much more intense damage than ash falls there are relatively few buildings near the immediate slopes of most volcanoes that may be impacted. While the fragility of crops, infrastructure, communication systems, aircraft and other assets, including people, to ash falls are of considerable importance (Blong 1984; Wilson et al. 2012; Volcanic Ashfall Impacts Working Group 2016), the development of ash fall vulnerability estimates is the most advanced for buildings (Jenkins et al., 2014). From an insurance 
perspective, they are by far the most valuable insured asset. Ash fall vulnerability estimates are also more easily developed for buildings as the mechanism through which damage occurs is typically distinct (loading), whereas for pyroclastic density currents, for example, hazard parameters include temperature and lateral pressure, as well as the duration of these impact mechanisms on the structure (Blong 2003; Spence et al. 2005; Jenkins et al. 2014).

Ash fall vulnerability and fragility functions (also known as curves) developed for specific building types link the local intensity of ash fall (thickness or loading) to probable levels of damage, often with levels of uncertainty described. We define 'vulnerability function' as a relationship expressing relative loss or economic cost as a function of hazard intensity; and 'fragility function' as a relationship expressing the probability of a level of impact being equalled or exceeded for a given hazard intensity (Rossetto et al., 2013). In this study, we have collated available building vulnerability and fragility functions for ash fall to assess how the choice of function affects estimates of building damage or loss. Specifically, we utilise a scenario which replays the 1815 cataclysmic eruption of Tambora (VEI 7) as an example of the immediate potential consequences for a limited number of building styles, and for the insurance industry, of a widespread volcanic ash fall event (Kandlbauer et al. 2013). Our aim is to highlight the sensitivity of loss and damage calculations to functions that describe the vulnerability of an asset to a volcanic hazard. Here, we concentrate on building response to volcanic ash fall.

In considering building vulnerability functions here, we simplify damage by neglecting building contents and potential damage to lifelines such as electricity, gas, and water supply that allow buildings to continue to be functional during and after ash fall. Our contribution focuses only on the vulnerability of (potentially insured) buildings in the Asia-Pacific region; this is an important constraint as in our area of interest only a few building roofs have been built to accommodate snow loads. Thus, we are not making comparisons across the full range of building types for which vulnerability functions have been developed. As we are only considering ash falls, heated ballistics leading to building or content ignition are not considered, but could be hazardous for more proximal (up to $10 \mathrm{~km}$ from the vent) buildings. We also ignore the potential consequences of subsequent corrosion damage caused by ash deposition on building components, as well as the costs of property clean-up, and ash and building debris disposal. In so limiting this discussion, we recognise the important and integrative studies of eruption hazards produced by the EXPLORIS (Baxter et al., 2008) and MIA-VITA (Jenkins and Spence, 2009; Jenkins et al., 2014) projects as well as recent advances in better understanding the impact of volcanic ash on critical infrastructure (Wilson et al., 2012) and the costs associated with ash clean-up and disposal (Hayes et al., 2015).

\section{Building vulnerability to ash fall}

Surveys of building damage are plentiful in the natural hazards literature, with whole journals almost entirely devoted to earthquake, windstorm or flood damage. In contrast, there is surprisingly little material published on the consequences for buildings in volcanic eruptions, particularly as the result of ash loading. Anecdotal material is summarised by Blong $(1981 ; 1984)$, and Spence et al. (1996) who studied building failures in Castellejos and Olangapo from a Pinatubo (1991) wet ash fall accumulation of $15-20 \mathrm{~cm}$. Pomonis et al. (1999) surveyed structures in the Azores and determined failure loads based in part on material testing of roof timbers. Spence et al. (2005) provided an analysis of static loads, the likely paths to roof failure, a consideration of four roof types, and an appendix summarising the recorded effects of ash falls on roofs. Spence et al. (2005) also extended the analysis of building damage recorded by Blong (2003) for the 1994 eruptions affecting Rabaul, Papua New Guinea. The latter study focussing on insured buildings, most of which were timber-framed.

Magill et al. (2006) collected data from the above studies to produce a vulnerability function that describes the relationship between ash thickness and percentage of total building replacement value, assuming timberframed buildings. By including probabilistic ash dispersal simulations and applying this function to residential buildings in Auckland, New Zealand, and also accounting for non-structural damage and clean-up costs, loss functions were generated which presented expected loss against Average Recurrence Interval (ARI).

The EXPLORIS project (Baxter et al., 2008) outlined a decade of important work - for present purposes, building damage from earthquake, ash fall and pyroclastic density currents were estimated for a number of European volcanoes. Zuccaro et al. (2008) provided a useful 5-fold classification of roof types for buildings around Vesuvio (Italy) and collapse probability functions for five roof typologies under varying ash loads. Importantly for the present study, seismic and ash fall building vulnerability classes showed a generally poor correlation. Spence et al. (2008a) applied their 4-fold roof classification to modelling the impact, in terms of building damage and casualties, of a sub-Plinian eruption at La Soufriere, Guadeloupe.

The MIA-VITA project (Jenkins and Spence, 2009; Jenkins et al., 2014) built upon the Europe-focused EXPLORIS work by developing building vulnerability functions for all volcanic hazards, with an emphasis on 
buildings more commonly found in tropical and developing countries. Case studies and vulnerability surveys were carried out in Indonesia, Philippines, Cape Verde, Guadeloupe and Martinique providing information on likely building types. Building vulnerability functions available at the time were then evaluated in order to develop a set of authoritative functions for five key roof types, which could be further adapted to a range of building types. For this study, building damage was considered with respect to the potential for loss of life, and as such a key assumption of the MIA-VITA study was that complete damage referred to collapse of the roof. However, from an economic perspective, complete damage refers to collapse of the entire building, including the roof. This difference is important when comparing functions.

All these studies emphasise the need to focus on static load rather than ash thickness as wet and dry densities of ash can vary widely from about 500 to $2000 \mathrm{~kg} / \mathrm{m}^{3}$ (Shipley, S.and Sarna-Wojcicki, A 1982; Blong 1984; Spence et al. 2005; Macedonio \& Costa 2012; Jenkins et al. 2014).

More recently the Global Assessment Report 2015 (GAR15) general workshop (see Maqsood et al., 2014) set out the development of regional vulnerability functions for the Asia-Pacific region for earthquake, wind, flood, tsunami and volcanic ash fall. To develop the GAR15 regional vulnerability functions, expected damage to the physical building fabric was based on hazard intensity, an expected mean damage index and expected variance. Several authors (RB, CM, TW) of this study participated in this workshop to separately prepare building vulnerability models for ash fall loading, which were included in 2015 for the first time in the Global Assessment Report. To assess the vulnerability to ash fall, GAR15 focused on 11 out of 47 building types (WAPMERR schema; Maqsood et al., 2014, p12), as well as 3 roof pitch categories: High $\left(>35^{\circ}\right)$, Medium $\left(6-35^{\circ}\right)$, and Low $\left(<6^{\circ}\right)$. Of those myriad building categories, only 25 were consequently considered in the GAR15 report. This was due to limited observed damage data, some building categories being regarded as unlikely and in order to limit the amount of work required. Terminology for the 25 building types considered is shown in Table 1. Eight benchmark functions (green squares in Table 1) were developed during the GAR15 workshop by the 10 attendees, with the aim that the remaining 17 (yellow squares in Table 1) would be developed individually with the results compiled by Geoscience Australia personnel. The eight functions developed in the workshop are shown in Fig. 1. The damage index on the Yaxis in Fig. 1 refers to the total cost of repairing the building fabric of a group of buildings exposed to volcanic ash fall divided by the total cost of fully rebuilding the same assets in the existing locality to current local building regulations (Maqsood et al., 2014, p8).

The GAR workshop was concerned only with loads imposed by wet ash on the basis that volcanic ash deposited dry, generally speaking for many parts of the world, will soon absorb rainfall. This is important as wet ash can achieve bulk densities and ash loads about double that of dry ash (cf. Blong, 2003; Macedonio and Costa 2012).

\section{Analysis of vulnerability functions}

Figure 1 shows vulnerability functions for eight building types based on the combined and considered view of all 'experts' present at the Geoscience Australia GAR workshop. Intuitively, the ordering of the functions for the eight building types makes good sense. However, these functions suppress the large variations in views that are apparent when vulnerability functions are developed by individuals or small groups of researchers, often utilising small subsets of observational data.

Figures 2, 3, 4, 5, 6 illustrate this variability for the five building types marked with \# in Table 1. Each figure shows the individual functions [E1-E3] developed by three of the 'experts' who took part in the GAR workshop - authors from this manuscript RB, CM and TW (not in numbered order). Presumably, each of the 'experts' at the workshop developed their functions on the basis of field experience, knowledge of the relevant literature and a range of (unknown) biases. The average functions shown in each of the five figures are based solely on functions E1-E3 with no weighting applied. The fourth function in each figure [E4] is derived from the MIA-VITA (2014) study, with this function developed by a separate group of experts. The MIA-VITA functions refer specifically to roof types, rather than overall building types, and are constructed on a different basis to the GAR15 functions. That is, the damage index in MIA-VITA refers only to damage to the roof structure and not the whole building structure. Intuitively, we would expect the MIA-VITA functions to estimate higher losses as roof collapse is likely to occur at lower loads than total building collapse.

Figures 2, 3, 4, 5, 6 illustrate the variability in individual expert's views of building vulnerability to ash fall. The equations for each function from each 'expert' and for each building type are shown in Table 2. An 'expert' may estimate more severe damage than that of the average function for one building type, but less severe damage than the average for another. For example, although E4 (MIA-VITA) estimates of vulnerability are generally higher than the estimates of others, that is not always the case (e.g. Fig. 5, for smaller ash loads on concrete frame, reinforced masonry buildings). 
Table 1 Global Assessment Report terminology for the 25 building categories considered in Maqsood et al. 2014). Green squares indicate the 8 building damage benchmark functions developed during the GAR15 workshop. Yellow squares indicate the building types for which damage indices were to be developed out of session. \# shows the 5 building types discussed in this paper for which damage indices/ash loading functions were developed by three of the 'experts' who participated in the GAR workshop (authors RB, CM and TW)

\begin{tabular}{|c|c|c|c|c|c|c|}
\hline $\begin{array}{l}\text { GAR15 } \\
\text { Label }\end{array}$ & Description & $\begin{array}{l}\text { Storey } \\
\text { Class }\end{array}$ & Storeys & $\begin{array}{l}\text { Roof } \\
\text { Pitch } \\
H=>35^{\circ}\end{array}$ & $\begin{array}{l}\text { Roof } \\
\text { Pitch } \\
M=6-35^{\circ}\end{array}$ & $\begin{array}{l}\text { Roof } \\
\text { Pitch } \\
L=<6^{\circ}\end{array}$ \\
\hline W1-ENG & $\begin{array}{l}\text { Wood, Light Frame }\left(\leq 5000 \mathrm{ft}^{2}\right) \text {, } \\
\text { engineered }\end{array}$ & $\begin{array}{l}\text { Low } \\
\text { Rise }\end{array}$ & $1-2$ & & & \\
\hline $\begin{array}{l}\text { W1- } \\
\text { NONENG }\end{array}$ & $\begin{array}{l}\text { Wood, Light Frame }\left(\leq 5000 \mathrm{ft}^{2}\right) \text {, } \\
\text { non-engineered }\end{array}$ & $\begin{array}{l}\text { Low } \\
\text { Rise }\end{array}$ & $1-2$ & $\#$ & & \\
\hline $\begin{array}{l}\text { W2/S3- } \\
\text { ENG }\end{array}$ & $\begin{array}{l}\text { Commercial and industrial, } \\
\text { engineered }\end{array}$ & $\begin{array}{l}\text { Low } \\
\text { Rise }\end{array}$ & $1-2$ & & & \\
\hline $\begin{array}{l}\text { W2/S3- } \\
\text { NONENG }\end{array}$ & $\begin{array}{l}\text { Commercial and industrial, } \\
\text { non-engineered }\end{array}$ & $\begin{array}{l}\text { Low } \\
\text { Rise }\end{array}$ & $1-2$ & & $\#$ & \\
\hline $\begin{array}{l}\text { C3L/RML- } \\
\text { ENG }\end{array}$ & $\begin{array}{l}\text { Concrete Frame/Reinforced } \\
\text { Masonry, engineered }\end{array}$ & $\begin{array}{l}\text { Low } \\
\text { Rise }\end{array}$ & $1-3$ & & & $\#$ \\
\hline $\begin{array}{l}\text { C3L/RML- } \\
\text { NONENG }\end{array}$ & $\begin{array}{l}\text { Concrete Frame/Reinforced } \\
\text { Masonry, non-engineered }\end{array}$ & $\begin{array}{l}\text { Low } \\
\text { Rise }\end{array}$ & $1-3$ & & & \\
\hline $\begin{array}{l}\text { C3M/RMM } \\
\text {-ENG }\end{array}$ & $\begin{array}{l}\text { Concrete Frame/Reinforced } \\
\text { Masonry, engineered }\end{array}$ & $\begin{array}{l}\text { Mid } \\
\text { Rise }\end{array}$ & $4-7$ & & & \\
\hline $\begin{array}{l}\text { C3M/RMM } \\
\text {-NONENG }\end{array}$ & $\begin{array}{l}\text { Concrete Frame/Reinforced } \\
\text { Masonry, non-engineered }\end{array}$ & $\begin{array}{l}\text { Mid } \\
\text { Rise }\end{array}$ & $4-7$ & & & \\
\hline URML-ENG & $\begin{array}{l}\text { Unreinforced Masonry Bearing } \\
\text { Walls, engineered }\end{array}$ & $\begin{array}{l}\text { Low } \\
\text { Rise }\end{array}$ & $1-2$ & & & \\
\hline $\begin{array}{l}\text { URML- } \\
\text { NONENG }\end{array}$ & $\begin{array}{l}\text { Unreinforced Masonry Bearing } \\
\text { Walls, non-engineered }\end{array}$ & $\begin{array}{l}\text { Low } \\
\text { Rise }\end{array}$ & $1-2$ & & & $\#$ \\
\hline PBC & $\begin{array}{l}\text { Post and Beam Construction } \\
\text { (informal settlements) }\end{array}$ & $\begin{array}{l}\text { Low } \\
\text { Rise }\end{array}$ & $1-2$ & & $\#$ & \\
\hline
\end{tabular}

These substantial differences could result from different experiences/context in viewing ash fall damage, variations in construction standards, building size or maintenance from one country to another, or just varying views of building damage and/or replacement costs. The empirical dataset from which estimates of building vulnerability can be drawn is very limited, with comprehensive ash fall building damage surveys confined to the eruptions of Pinatubo in 1991 (Spence et al., 1996) and Rabaul in 1994 (Blong, 2003). Figure 7 shows that our four 'expert' views are not extreme when compared with the very wide range of vulnerabilities suggested by all eight GAR15 'experts'. Figure 7 includes the views of three 'experts' in our manuscript, authors of this paper who attended the GAR15 workshop. We have not attempted to evaluate the uncertainties or sources of bias in this methodology. At one extreme an 'expert' might have most experience with ash loads to timberframed structures in an Asia-Pacific country where buildings are designed for earthquake and wind loading codes and are adapted for heavy snow falls. At the other extreme an 'expert' may be more familiar with ash loads to timber-framed buildings where the earthquake code is only occasionally complied with, snow never falls, and there is no wind loading code. While such variations are inherent in compilations such as the GAR15 report, it is reasonable to assume that individual 'experts' have been internally consistent in developing functions for a range of building types.

In the GAR15 study as illustrated in Fig. 7, a weighted view was included. Two methods for weighting were compared; one used equal weighting for all experts; the other relied on the confidence the experts expressed in their function - low, medium, high. Differences in the two weights were reportedly quite low for each comparison (a maximum of approximately 0.05 in the damage index for any given ash load), compared with the wide dispersion of the 'experts' responses (Maqsood et al., 


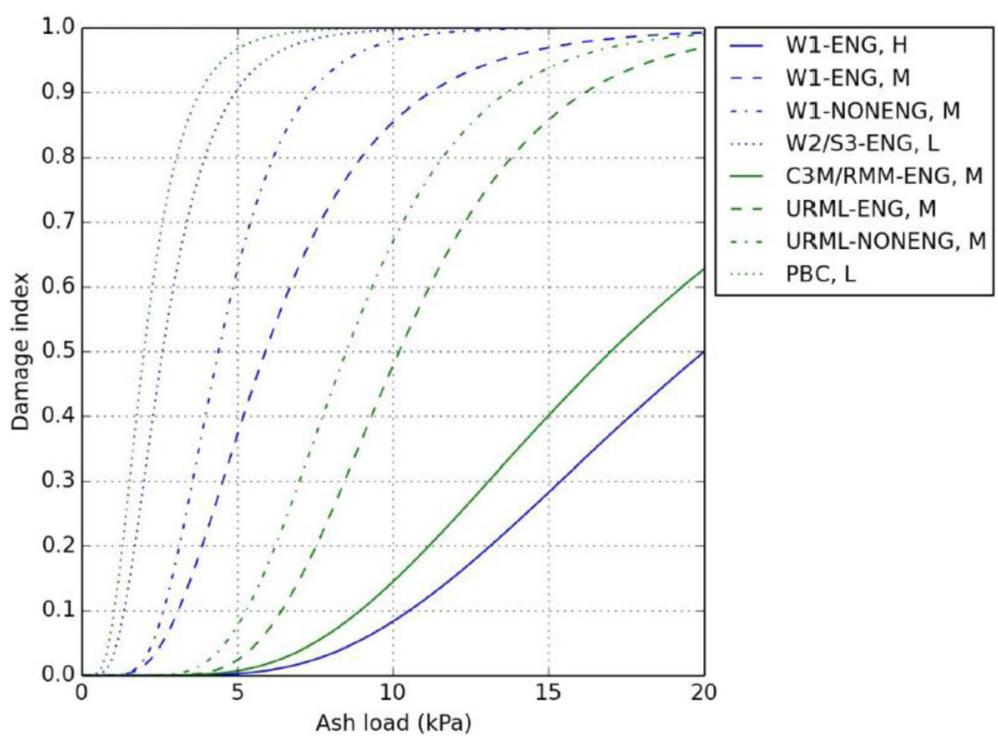

Fig. 1 The eight vulnerability functions for buildings exposed to volcanic ash fall derived during the GAR15 workshop by a group of 'experts'. Building types described in Table 1. $H=$ High pitched roof $\left(>35^{\circ}\right), M=$ Medium $\left(6-35^{\circ}\right)$, and $L=$ Low pitched roof $\left(<6^{\circ}\right)$ as shown in Table 1. Damage Index is defined in the text above (figure adapted from Maqsood et al., 2014, p93)

2014, p101). The comparison shows that while the GAR15 methodology considers roof pitches in 3 categories $\left(<6^{\circ}, 6-35^{\circ}\right.$, and $>35^{\circ}$ - see Table 1$)$, the variability shown in Fig. 7 for a single roof pitch of $<6^{\circ}$ suggests this is an unnecessary complication given our limited understanding of structural responses to ash loads. Additionally, the MIA-VITA analysis does not categorise multiple roof pitches, but simply differentiates between flat and pitched roofs. There is limited evidence in the literature to support a relationship between roof slope and angles of sliding friction for volcanic ash, although recent experiments suggest that dry ash is unlikely to slide off roof pitches less than about $35^{\circ}$, and that wet ash will adhere to the roof covering at even higher pitches (Hampton et al., 2015). Somewhat conversely, Spence et al. (1996) found that buildings with steeper roof pitches tended to suffer worse damage, although none of the roofs had slopes steep enough to shed ash. It is not clear why in this case roofs with steeper pitch were more severely damaged. Further empirical, experimental and/or theoretical studies are needed to justify or modify the three categories of roof pitch chosen for the

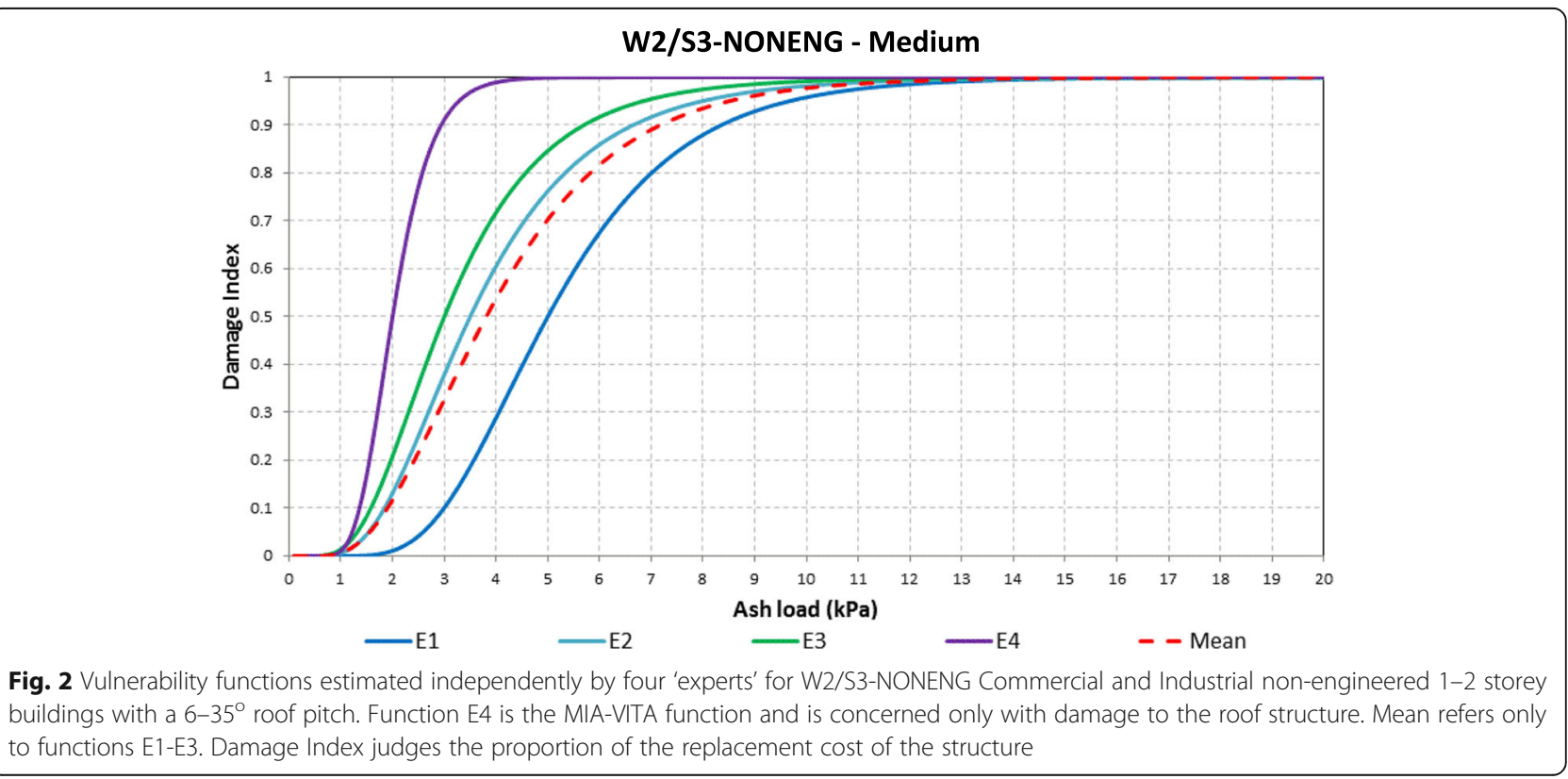




\section{URML-ENG - Low}

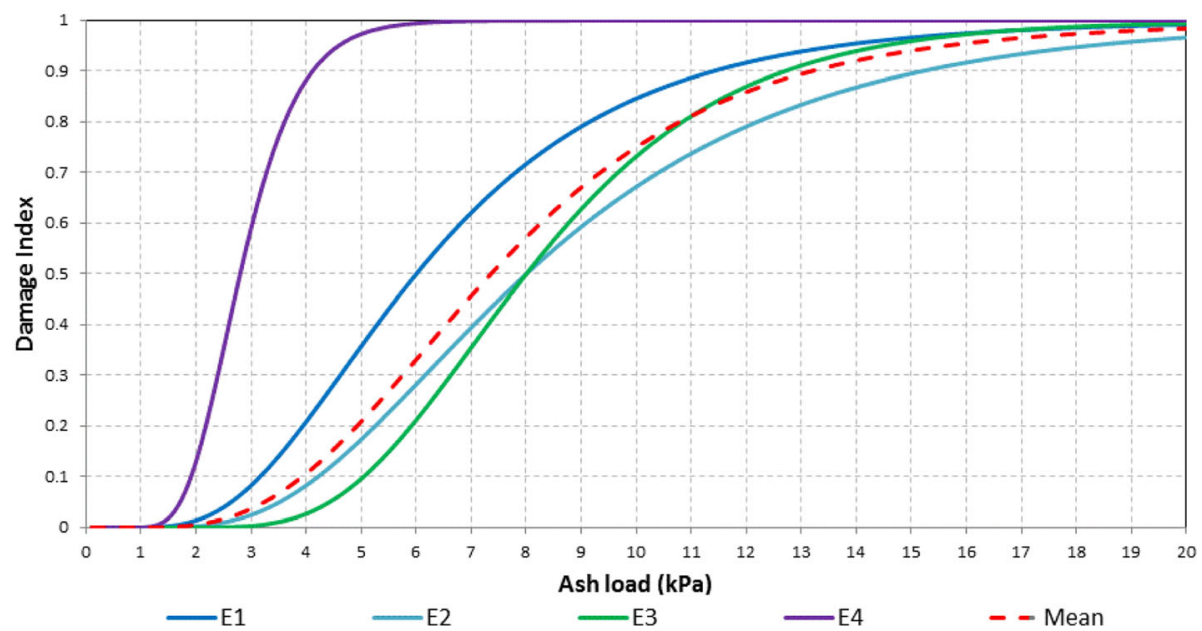

Fig. 3 Vulnerability functions estimated independently by four 'experts' for URML-ENG Unreinforced Masonry Bearing Walls, non-engineered with a Low roof pitch $<6^{\circ}$. Function E4 is the MIA-VITA function and refers only to damage to the roof structure. Mean refers only to functions E1-E3. Damage index refers to the replacement cost of the structure

GAR15 study, as there is no clear evidence to support the choices. By contrast, there is empirical evidence to suggest that long-span roofs are particularly vulnerable to roof collapse (Blong, 2003; Spence et al., 1996), yet these were not considered separately within the GAR15 classifications.

\section{Vulnerability estimation for insurance purposes}

Insurers and reinsurers use catastrophe models developed by vendors such as Risk Management Solutions (RMS), Applied Insurance Research (AIR), Risk Frontiers or Impact Forecasting, or on open-source platforms such as Oasis, to estimate potential losses on a probabilistic basis from a range of natural hazards. Most insurance models are concerned with potential losses to buildings but some models also consider, for example, potential losses to infrastructure, agriculture, business interruption or workers' compensation policies. Models typically contain catalogues of numerically simulated hazard events with associated probabilities that are combined with vulnerability functions and insured portfolio information to calculate loss statistics. Earthquake ground shaking and typhoon/cyclone wind models are the

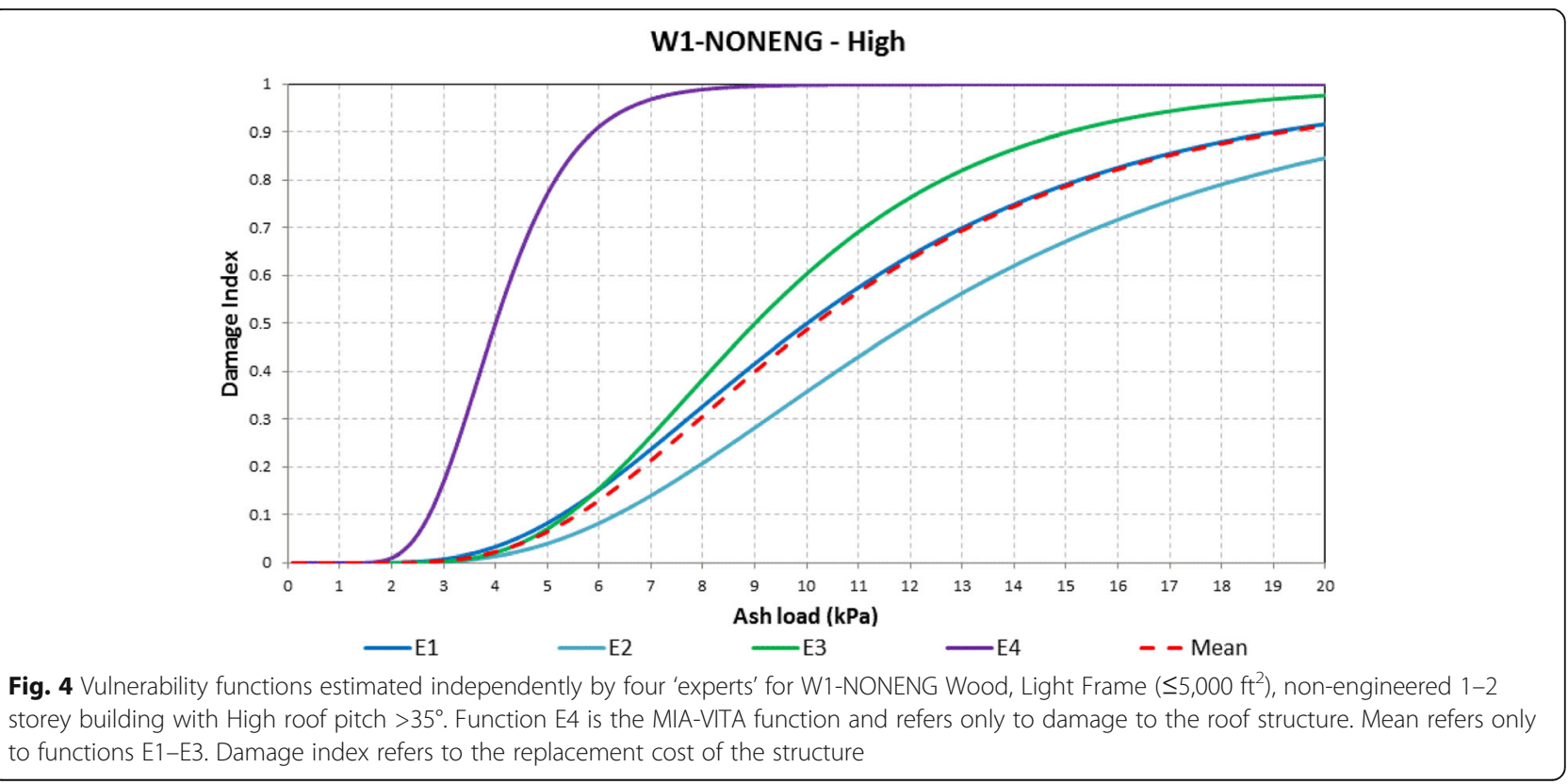




\section{C3/RML-ENG - Low}

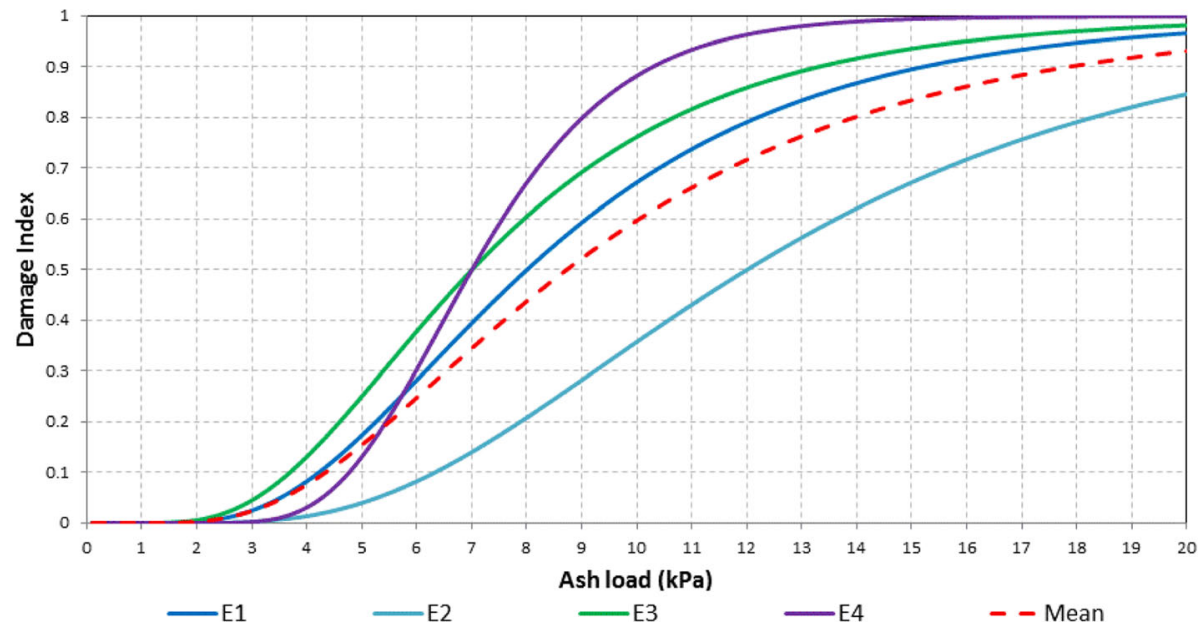

Fig. 5 Vulnerability functions estimated independently by four 'experts' for C3RML-ENG Concrete Frame/Reinforced Masonry, engineered 1-3 storey building with a Low roof pitch $<6^{\circ}$. Function E4 is the MIA-VITA function and refers only to damage to the roof structure. Mean refers only to functions E1-E3. Damage index refers to the replacement cost of the structure

most common and sophisticated, but models are also available for flood losses, storm surge, tsunami, hail and, to a lesser extent, volcanic ash fall. Scenarios of various levels of sophistication may also be used to estimate losses, particularly where probabilistic catastrophe models are not available or to consider elements not included in the models.

Our purpose here is the estimation of potential damage resulting from volcanic ash fall to an idealised insurance portfolio of buildings and to illustrate the dependence of loss estimation on variations in assessed building vulnerability. The portfolio of assets of interest to an individual insurer may contain millions of buildings of various construction classes even in a single country. The detail of information available regarding individual buildings might be quite variable, but a model needs to be able to assign each insured asset to a building class and a location (which indicates the hazard intensity for a specific ash fall, for example). For any location, a model can then use an appropriate vulnerability function to estimate the potential damage to the given building type produced by the simulated hazard intensity for that simulated hazard event. Thus, data preparation is a large part of the effort required in

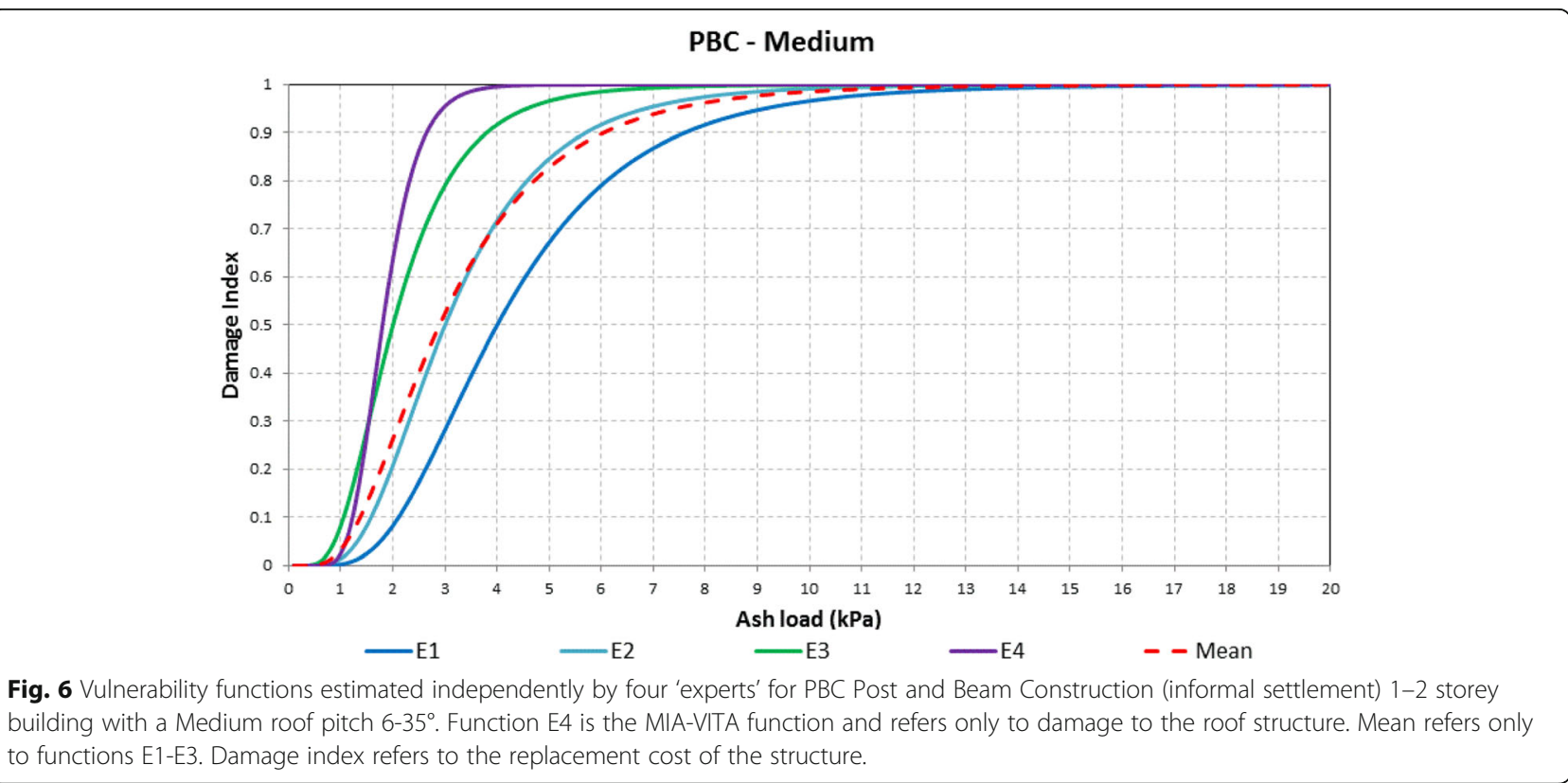


Table 2 Parameters for a Log-Normal distribution were derived by the four 'experts' to develop vulnerability functions for each building type which determine expected damage to a structure, using ash load (kpa) as the input parameter

\begin{tabular}{|c|c|c|c|c|c|c|c|}
\hline \multicolumn{3}{|l|}{ Description } & \multirow{2}{*}{$\begin{array}{l}\text { Wood, Light } \\
\text { Frame, } \\
\text { nonengineered } \\
\text { High ( }>35 \text { deg) }\end{array}$} & \multirow{2}{*}{$\begin{array}{l}\text { Commercial and } \\
\text { Industrial, } \\
\text { nonengineered } \\
\text { Medium (6-35 deg) }\end{array}$} & \multirow{2}{*}{$\begin{array}{l}\text { Concrete Frame/ } \\
\text { Reinforced Masonry, } \\
\text { engineered } \\
\text { Low (<6 deg) }\end{array}$} & \multirow{2}{*}{$\begin{array}{l}\text { Unreinforced Masonry } \\
\text { Bearing Walls, } \\
\text { engineered } \\
\text { Low }(<6 \text { deg) }\end{array}$} & \multirow{2}{*}{$\begin{array}{l}\text { Post and Beam } \\
\text { Construction (informal } \\
\text { at low end) } \\
\text { Low }(<6 \text { deg) }\end{array}$} \\
\hline Roof Pitch & & & & & & & \\
\hline \multirow{12}{*}{$\begin{array}{l}\text { Vulnerability } \\
\text { Functions }\end{array}$} & E1 & Median & 10.0 & 5.0 & 8.0 & 6.0 & 4.0 \\
\hline & & Beta & 0.50 & 0.40 & 0.50 & 0.50 & 0.50 \\
\hline & & Confidence & Med & Low & Low & Low & Low \\
\hline & E2 & Median & 12.0 & 3.5 & 12.0 & 8.0 & 3.0 \\
\hline & & Beta & 0.50 & 0.50 & 0.50 & 0.50 & 0.50 \\
\hline & & Confidence & Med & Low & Low & Low & Low \\
\hline & E3 & Median & 9.0 & 3.0 & 7.0 & 8.0 & 2.0 \\
\hline & & Beta & 0.40 & 0.50 & 0.50 & 0.36 & 0.50 \\
\hline & & Confidence & Med & Low & Med & Low & Med \\
\hline & E4 & Median & 4.0 & 2.0 & 7.0 & 2.8 & 1.8 \\
\hline & & Beta & 0.30 & 0.30 & 0.30 & 0.30 & 0.30 \\
\hline & & Confidence & Med & Low & Low & Low & Low \\
\hline
\end{tabular}

running a loss model. As an insurer is generally interested in all hazards that could potentially produce losses to a portfolio of buildings it is common to use the one set of building descriptors even though different building attributes may be important for each peril. It is unlikely that the GAR15 schema would be used by insurers for two major reasons: (i) it bears little relationship to the limited information that insurers hold about the buildings that they insure; and (ii) it is too complicated; building schemes used by insurers and by model vendors usually include only a limited number (maybe a dozen or less) building types.

While the MIA-VITA scheme provides the most rational building descriptions for assessing vulnerability to volcanic ash fall, much of the data required to assign an insured building to a roof class would not be held by an insurer. For example, long span roofs are not identified in insurance typologies, and yet have proven important

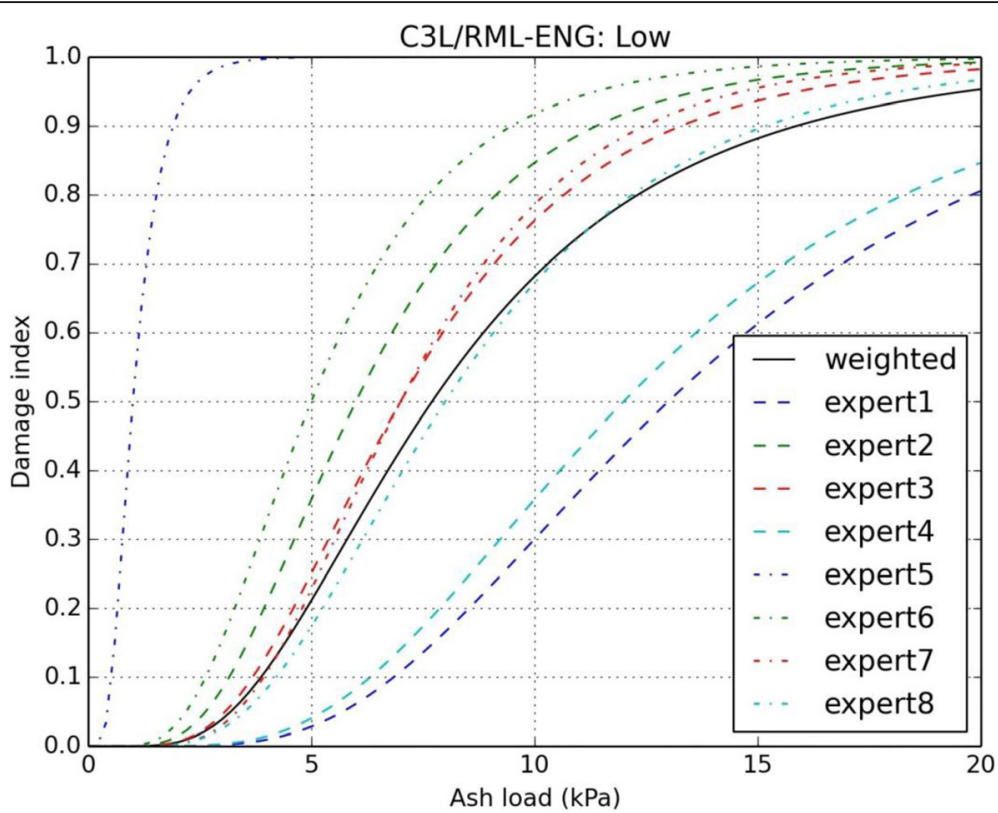

Fig. 7 Estimates of building vulnerability for C3RML-ENG Concrete Frame/Reinforced Masonry, engineered 1-3 storey building with a Low roof pitch $<6^{\circ}$ recorded for eight experts who took part in the GAR15 workshop. This figure is directly comparable with, and includes the three expert views in, Fig. 5. We are unsure which of the weighted views described in the text is shown here (adapted from Maqsood et al., 2014, p102, p522) 
in determining building vulnerability to ash fall (e.g. Spence et al., 1996). Should the roof pitch (beyond the flat/pitched designation of the MIA-VITA curves) be as important as the GAR15 scheme would suggest, then correlation with insurance classes would be even more difficult. Here, we have used our judgement to correlate the buildings contained within typical insurance classes with our vulnerability typologies (Table 3), e.g. a commercial or industrial building of light metal (RMS 4B) is assumed to have a large roof span, and concrete roof decks (RMS 3A, 3B, 4A) are assumed to be flat, rather than pitched. However, the assignments, and resulting vulnerabilities and loss estimates, are subject to uncertainty without a field survey or further information to ground-truth our assumptions.

These issues are not uncommon for other natural hazard loss models, as there is often a mismatch between insurer information and model requirements. Here we 'map' GAR15 building classes and MIA-VITA roof classes to RMS construction types (Table 3). 'Mapping' one construction schema to another is not a precise art and we do not guarantee that our 'map' is superior to others that might be suggested. The majority of vulnerability functions are developed on the basis of field surveys and detailed knowledge of the building types. Guidelines for simplifying the building typology information is required in order to support the global use of vulnerability functions, as has been done for earthquake (Spence et al., 2008b), although this would best be done with much larger damage datasets than currently exist.

\section{Application of ash fall vulnerability functions - 1815 Tambora eruption}

To test the importance of these perceived differences in the vulnerability of buildings to ash fall we have constructed an insurance-related example based on an artificial portfolio of risks for Indonesia and a repeat of the main phase of the 1815 eruption of Tambora volcano on Sumbawa Island, Indonesia. The ash fall from this VEI 7 eruption is generally considered to have only affected what is current-day Indonesia, Timor Leste and parts of Malaysia. Figure 8 is derived from the Kandlbauer et al. (2013) isopach with additional isopachs interpolated by eye (see figure caption). For the purposes of comparing vulnerability functions we have assumed that every square kilometre of Indonesia is populated by just five buildings - one of each type of the five \# buildings types in Table 1, with the vulnerabilities to ash fall shown in Figures 2, 3, 4, 5, 6.

For our calculations, a constant thickness of ash is assumed to have fallen between isopachs, equivalent to the smallest thickness of the bounding isopachs. Table 4

Table 3 A 'map' relating Risk Management Solutions construction classes (RMS, 2011) to the MIA-VITA schema (Jenkins et al., 2014) and a number of GAR15 building construction types. Those building types highlighted in red in the last column are the five construction classes considered in this paper. The mean and range of collapse loads are from Jenkins et al. (2014) for MIA-VITA roof types

\begin{tabular}{|c|c|c|c|c|}
\hline $\begin{array}{c}\text { RMS } \\
\text { Construction Types }\end{array}$ & $\begin{array}{l}\text { Roof } \\
\text { class }\end{array}$ & MIA-VITA Roof Class Description & $\begin{array}{l}\text { Mean (interdecile } \\
\text { range) } \\
\text { Collapse Load (kPa) }\end{array}$ & GAR15 \\
\hline $\begin{array}{l}\text { 1A - Light Wood Frame } \\
\text { 2A- Weak Masonry, } \\
\text { Adobe }\end{array}$ & $\begin{array}{l}\text { MIA- } \\
\text { VITA_A }\end{array}$ & $\begin{array}{c}\text { Weak timber boards on timber rafters/trusses; } \\
\text { Metal sheet roofs on timber rafters/trusses, in old or poor condition; } \\
\text { Tiles on timber rafters/trusses, of old or poor condition; } \\
\text { Vaulted masonry. }\end{array}$ & $\begin{array}{c}1.8 \\
(1.2 \text { to } 2.6)\end{array}$ & $\begin{array}{l}\text { Post and Beam Construction (Informal Housing) Low, Medium } \\
\text { and High Pitch }\end{array}$ \\
\hline 4B - Light Metal & $\begin{array}{l}\text { MIA- } \\
\text { VITA_B }\end{array}$ & Long span roofs with metal sheet or fibre reinforced concrete sheets. & $\begin{array}{c}2.0 \\
(1.4 \text { to } 2.9) \\
\end{array}$ & $\begin{array}{c}\text { W2/S3-ENG Medium and Low Pitch } \\
\text { W2/S3-NONENG Medium and Low Pitch }\end{array}$ \\
\hline $\begin{array}{l}\text { 2B-URM } \\
\text { 3C- Reinforced } \\
\text { Concrete with Wood or } \\
\text { Metal Roof Deck }\end{array}$ & $\begin{array}{l}\text { MIA- } \\
\text { VITA_C }\end{array}$ & $\begin{array}{l}\text { Metal sheet roofs on timber rafters/trusses, in average condition; } \\
\text { Tiles on timber rafters/trusses, in average or good condition. }\end{array}$ & $\begin{array}{c}2.8 \\
\text { (1.9 to } 4.1)\end{array}$ & $\begin{array}{l}\text { W1-ENG Medium Pitch } \\
\text { W1-NONENG Medium Pitch } \\
\text { URML-ENG Low, Medium and High Pitches } \\
\text { URML-NONENG Low, Medium and High Pitches }\end{array}$ \\
\hline $\begin{array}{l}\text { 1B- Heavy Timber } \\
\text { 2C-Structural Masonry } \\
\text { 4C-Steel Frame with } \\
\text { wood or metal Roof } \\
\text { Deck }\end{array}$ & $\begin{array}{l}\text { MIA- } \\
\text { VITA_D }\end{array}$ & $\begin{array}{l}\text { Metal sheet roofs on timber rafters/trusses, in good condition; } \\
\text { Strong timber on timber rafters/trusses in average or good condition. }\end{array}$ & $\begin{array}{c}4.0 \\
(2.7 \text { to } 5.9)\end{array}$ & $\begin{array}{l}\text { W1-ENG High Pitch } \\
\text { W1-NONENG High Pitch }\end{array}$ \\
\hline $\begin{array}{c}\text { 3A-Reinforced } \\
\text { Concrete with Concrete } \\
\text { Roof Deck } \\
\text { 3B - Precast RC with } \\
\text { Concrete Roof Deck } \\
\text { 4A - Steel Frame with } \\
\text { concrete Roof Deck }\end{array}$ & $\begin{array}{l}\text { MIA- } \\
\text { VITA_E }\end{array}$ & $\begin{array}{l}\text { Flat reinforced concrete roof designed for access and generally in } \\
\text { good condition }\end{array}$ & $\begin{array}{c}7.0 \\
\text { (4.8 to } 10.3 \text { ) }\end{array}$ & $\begin{array}{l}\text { C3/RML-ENG Medium and Low Pitch } \\
\text { C3/RML-NONENG Medium and Low Pitch } \\
\text { C3/RMM-ENG Medium and Low Pitch } \\
\text { C3/RMM-NONENG Medium and Low Pitch }\end{array}$ \\
\hline
\end{tabular}




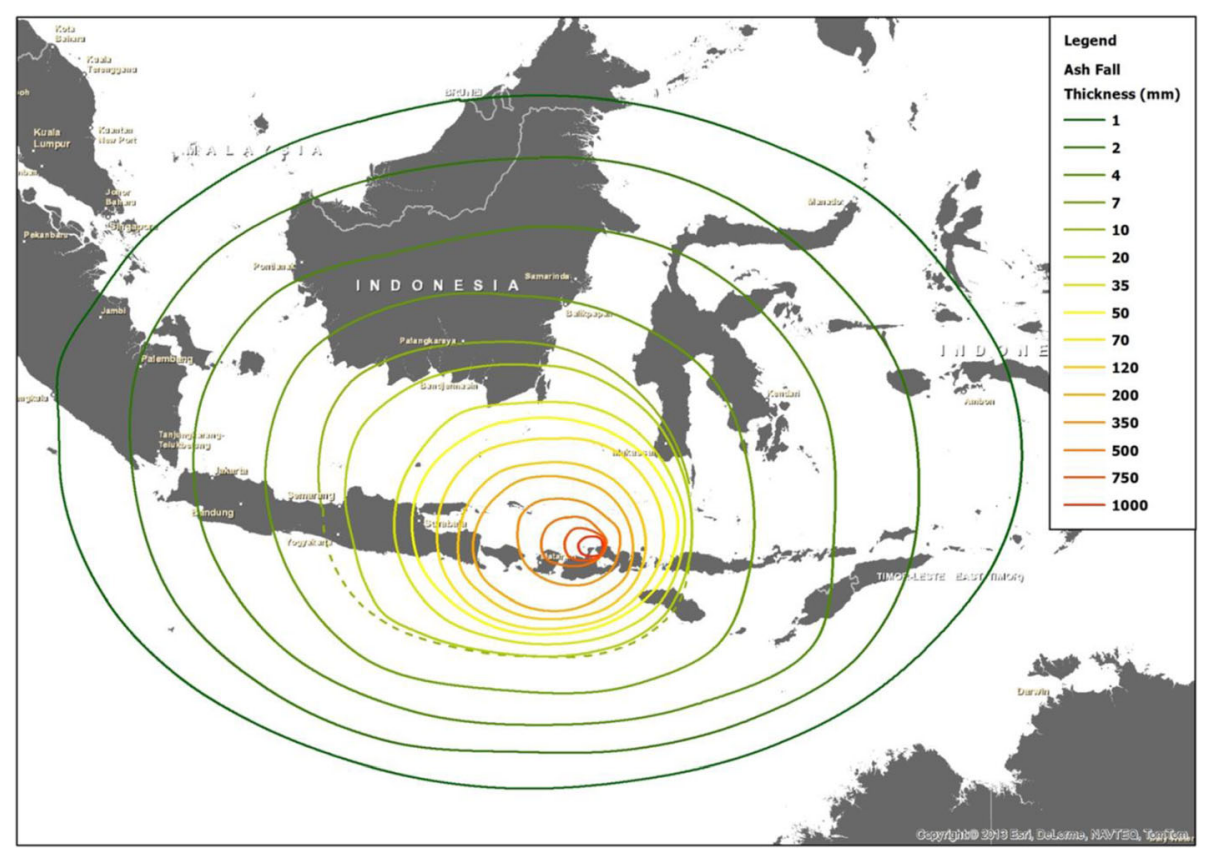

Fig. 8 Ash fall from the 1815 VEl 7 eruption of Tambora based on Kandlbauer and Sparks (2013) and, to a lesser extent, the isopachs of Self et al. (1984). Additional isopachs between 2 and $35 \mathrm{~mm}$ (inclusive), between 70 and $120 \mathrm{~mm}$ and those $350 \mathrm{~mm}$ and greater, as well as the southern portion of the $10 \mathrm{~mm}$ (dashed line) isopach, have been interpolated by eye

Table 4 The areas experiencing each thickness of ash fall in the repeat Tambora 1815 scenario eruption. Areas covered below $10 \mathrm{~mm}$ are given for illustrative purposes as these areas would still sustain large disruptions as the result of ash fall

\begin{tabular}{ll}
\hline Ask Thickness $(\mathrm{mm})$ & Land Coverange Area $(\mathrm{sqkm})$ \\
\hline $1-2$ & 236,353 \\
$2-4$ & 362,026 \\
$4-7$ & 318,945 \\
$7-10$ & 178,769 \\
$10-20$ & 58,155 \\
$20-30$ & 58,042 \\
$35-50$ & 14,254 \\
$50-70$ & 11,479 \\
$70-120$ & 7,918 \\
$120-200$ & 6,690 \\
$200-350$ & 11,456 \\
$350-500$ & 9,738 \\
$500-750$ & 3,315 \\
$750-1000$ & 961 \\
1000 & 765 \\
\hline
\end{tabular}

shows the total land area between each pair of isopachs on Fig. 8. It follows that in this example, the total number of buildings experiencing each ash fall thickness is $5 \times$ the land area (five buildings per square kilometre).

With each square kilometre containing an equal number of buildings of the same five construction types it is possible to calculate a vulnerability function that combines Figures 2, 3, 4, 5, 6 into a single function for each of the four 'experts' involved in the study. These were averaged by taking the average from all curves, excluding the E4 function (MIA-VITA), for each construction type (applying no weightings) and then fitting a Log-normal distribution to the outcome to derive parameters used in our analysis below. As we are concerned with ash thickness here, ash loads were converted by assuming an ash deposit density of $0.0162 \mathrm{kPa} / \mathrm{mm}\left(1620 \mathrm{~kg} / \mathrm{m}^{3}\right)$, a figure derived from ash fall thickness and bulk density recorded after the Rabaul eruption (Blong 2003). Figure 9 summarises these data. The E4 function (MIA-VITA) is for roof structures only, rather than the whole building. These data can also be summarised to show the average Damage Index for each building class summarised over all the buildings experiencing ash fall for each 'expert' (Fig. 10). Given the variations in expert views shown in Figures 2, 3, 4, 5, 6, the variations in Fig. 10 are hardly surprising.

The distribution of damage can be further summarised (Fig. 11) to indicate that nearly all the damage occurs in areas receiving between 200 and $1000 \mathrm{~mm}$ of ash fall. 


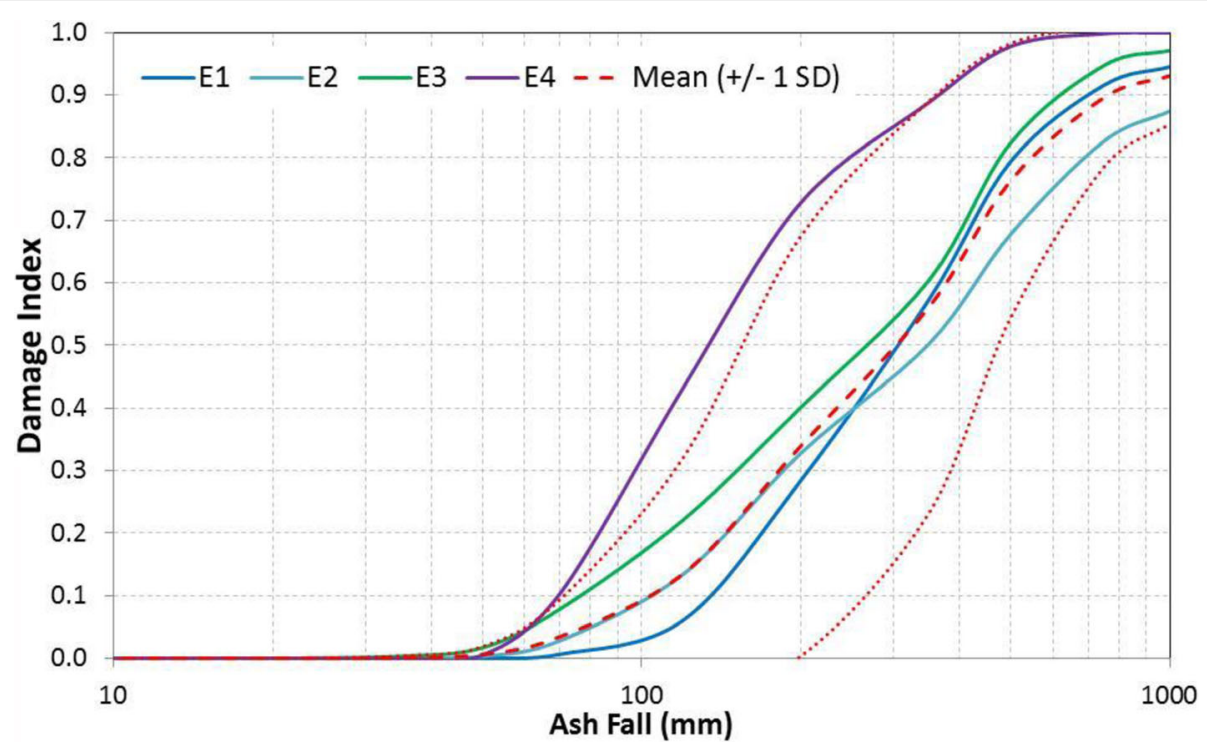

Fig. 9 Damage Index - ash fall thickness relationships for four 'experts'. The dotted lines represent the range of uncertainty (+/- 1 standard deviation) in the mean, highlighting that the greatest uncertainty exists between 800 and $1000 \mathrm{~mm}$ ash fall thicknesses; i.e. the range where the majority of the damage occurs (see Fig. 11)

Ash falls of less than $10 \mathrm{~mm}$ contribute a very minor amount of damage in this scenario while areas receiving $>1000 \mathrm{~mm}$ and $10-50 \mathrm{~mm}$ together constitute only a few percent of the total damage. This pattern depends on the distribution of land and sea and the mapped ash fall and these observations cannot be generalised to other areas or eruptions.

\section{Conclusions}

In this paper, we compare and contrast existing vulnerability functions that have been developed for volcanic ash fall on buildings, and apply them to a hypothetical building portfolio impacted by a modern-day Tambora 1815 eruption scenario. We found there is considerable variability in the different vulnerability estimates even for reasonably tightly specified construction types, which contributed to large uncertainties when estimating potential building damage and loss. This variability suggests there are very divergent views on the vulnerability of buildings to ash fall, on the levels of damage attributable to specified ash loadings, wide variations in building resilience within the specified construction type, and

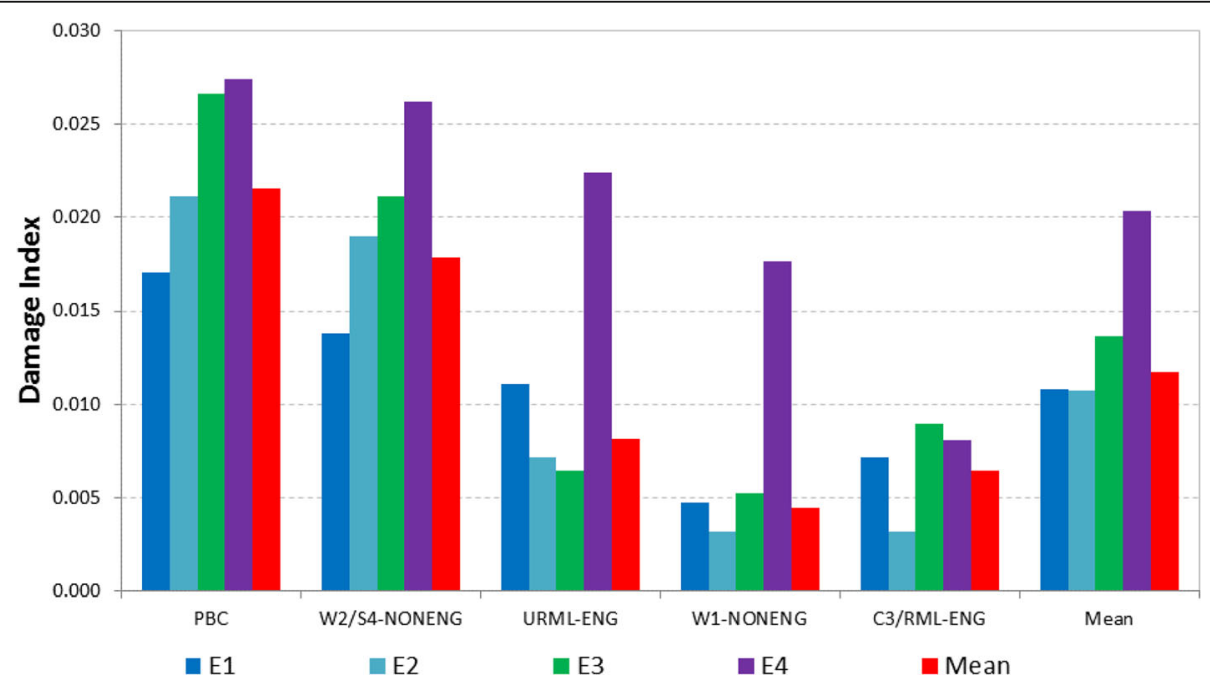

Fig. 10 The Damage Index for each of five building types and each 'expert', averaged across all buildings experiencing ash fall. In each set of columns, means refer only to Experts E1-E3 


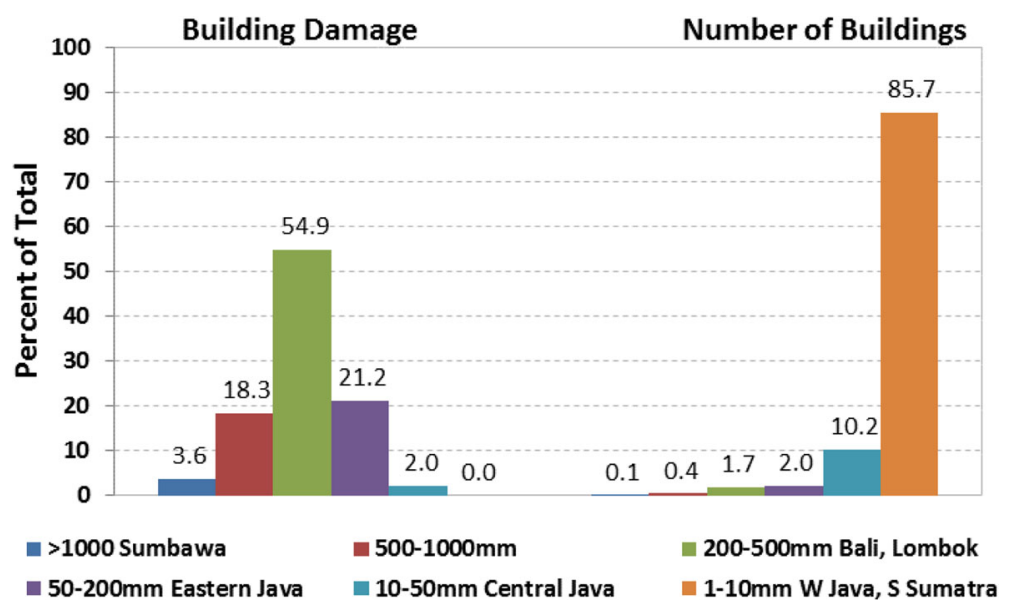

Fig. 11 The majority of building damage in the Tambora eruption scenario occurs in areas receiving ash falls of $200-500 \mathrm{~mm}$ of ash. The same area represents roughly $2 \%$ of the total number of buildings. Contribution to the total damage in areas receiving $<10 \mathrm{~mm}$ of ash ( $86 \%$ of buildings) are negligible and damage in areas receiving $>1000 \mathrm{~mm}(<1 \%$ of buildings) and $10-50 \mathrm{~mm}$ (10\% of buildings) add only a few percent to the total. The regional names in the figure are indicative only - refer to Fig. 8

limited experience (or different experiences) amongst the 'experts' in assessing building damage. It is also likely that there are varying views on the replacement values of building components, although only one view (that of the GAR15 workshop) was used here. This variability is hardly surprising given the lack of detailed and published studies of building damage resulting from ash fall.

A review of other GAR15 workshop results (Earthquake, Wind, Flood, Tsunami) suggests just as wide a divergence of expert views for other perils, with the possible exception of Wind (see Maqsood et al., 2014). In turn, the vast overlap in vulnerabilities may imply that there are far too many building types in the GAR/ WAPMEER schema, and thus suggests that a much simpler scheme of construction characteristics would result in little, if any, loss of vulnerability information. This is particularly important given there is too little information available about the characteristics of existing buildings to place most individual buildings into the GAR schema with any reliability.

This study also challenges the perception that the insurance industry is widely believed to have full information about building characteristics. The GAR15 and the RMS construction class schemes are dominated by the input of structural engineers with experience of earthquake ground shaking and wind loading codes, but may not contain the required attribute information to evaluate volcanic ash impacts. We need to question how appropriate such schemes might be for volcanic ash loadings and (for that matter), flood or tsunami vulnerabilities. Additionally, mapping of the GAR15 building typologies to MIA-VITA and schemes such as RMS introduces other potential sources of error, and we suggest that the GAR15 schema is not usable for practical insurance purposes. For example, the GAR15 schema differentiates three classes of roof slope for volcanic ash loadings. In our view the importance of the roof slope in regards to roof or building damage is not well known, hence it is uncertain if the threefold division at $6^{\circ}$ and $35^{\circ}$ define the appropriate categories. Further, the sliding friction coefficients for volcanic ash or how these might vary for different roofing materials is another important aspect to consider for future modelling, as well as the loads imposed on other building elements, or the consequences for those elements when ash is shed from higher to lower surfaces.

Consequently, future studies need to consider which building characteristics might be the most appropriate for volcanic ash loading and vulnerability assessment. The MIA-VITA schema (Table 3, columns 2 and 3) would appear to address this issue, but few existing databases would capture the necessary information. More studies of actual damage and large-scale laboratory testing are required before we can satisfactorily map roof characteristics to insurance and other building databases reliably.

Comparisons of vulnerability models (for example, Fig. 7), and hence insurance losses or replacement costs to repair buildings suggest we should not base too many conclusions on the views of a single 'expert'. On the other hand, if we have the views of a number of experts how do we appropriately weight their views as simple averaging is not sufficient. And ultimately, if we were to use a weighting scheme based on expert elicitation for future scenarios (cf. Aspinall, 2010), do we have sufficient information to adequately assess the expertise of the available 'experts'? 


\section{Abbreviations}

AIR: Applied Insurance Research; C3RML-ENG: Concrete Frame/Reinforced Masonry, engineered $1-3$ storey building with a Low roof pitch $<6^{\circ}$; EXPLORIS: Explosive Eruption Risk and Decision Support For EU Populations Threatened By Volcanoes; GAR: Global Assessment Report; GDP: Gross Domestic Product; MIA-VITA: Mitigate and Assess risk from Volcanic Impact on Terrain and human Activities; PBC: Post and Beam Construction (informal settlement) 1-2 storey building with a Medium roof pitch 6-35; RMS: Risk Management Solutions; URML-ENG: Unreinforced Masonry Bearing Walls, non-engineered with a Low roof pitch $<6^{\circ}$; VEl: Volcano Explosivity Index; W1-NONENG: Wood, Light Frame $\left(\leq 5,000 \mathrm{ft}^{2}\right)$ - non-engineered $1-2$ storey building with High roof pitch $>35^{\circ}$; W2/S3-NONENG: Commercial and Industrial non-engineered 1-2 storey buildings with a 6-35 roof pitch; WAPMERR: World Agency of Planetary Monitoring and Earthquake Risk Reduction

\section{Acknowledgements}

We thank Geoscience Australia for hosting the GAR15 Workshop on Volcanic Ash Vulnerability in Canberra, Australia, in November, 2013 and for encouraging (and funding) three of the authors to take part. We are also grateful for the detailed and insightful comments of Sebastian Biass, Chris Gregg and an anonymous reviewer, which greatly improved the manuscript.

\section{Funding}

TW contributions are supported by New Zealand Ministry of Business, Innovation and Employment's Natural Hazard Research Platform contract C05X0804. JK was supported by the AXA Research Fund (SM6536).

\section{Authors' contributions}

RB conceived and wrote much of the original manuscript based on our joint presentation of some of the results at the Cities on Volcanoes conference in Jogjakarta in 2014. All authors have contributed to, read, modified and approved the final manuscript.

\section{Competing interests}

The authors declare that they have no competing interests.

\section{Author details}

${ }^{1}$ Aon Benfield Asia-Pacific, Sydney, Australia. ${ }^{2}$ Earth Observatory Singapore, Nanyang Technological University, Singapore, Singapore. ${ }^{3}$ Department of Environmental Sciences, Risk Frontiers, Macquarie University, Sydney, Australia. ${ }^{4}$ Geological Sciences, University of Canterbury, Christchurch, New Zealand. ${ }^{5}$ Department of Earth Sciences, University of Bristol, Bristol, United Kingdom.

Received: 11 May 2016 Accepted: 21 December 2016

Published online: 26 January 2017

\section{References}

Aspinall W. A route to more tractable expert advice. Nature. 2010;463(7279):294-5. Baxter PJ, Neri A, Blong R, (Editors). Special Issue: Evaluating explosive eruption risk at European volcanoes. J Volcanol Geothermal Res. 2008;78(3):v-viii.

Blong R. Building damage in Rabaul, Papua New Guinea, 1994. Bull Volcanol. 2003:65(1):43-54.

Blong, R.J., 1981. Some effects of tephra falls on buildings. In: S. Self and R.S.J. Sparks (Editors), Tephra studies. Proceedings NATO Advanced Studies Institute, Laugarvatn and Reykjavik, June 18-29, 1980, pp. 405-420.

Blong RJ. Volcanic hazards: a sourcebook on the effects of eruptions. Sydney: Academic Press Australia; 1984. pp. 424.

Hampton SJ, Cole JW, Wilson G, Wilson TM, Broom S. Volcanic ashfall accumulation and loading on gutters and pitched roofs from laboratory empirical experiments: Implications for risk assessment. J Volcanol Geotherm Res. 2015;304:237-52

Hayes JL, Wilson TM, Magill C. Tephra fall clean-up in urban environments. J Volcanol Geotherm Res. 2015:304:359-77.

Jenkins, S. and Spence, R., 2009. Vulnerability curves for buildings and agriculture, Technical report D4.b for EU FP7-ENV project MIA-VITA, contract number 211393.

Jenkins SF, Spence RJS, Fonseca JFBD, Solidum RU, Wilson TM. Volcanic risk assessment: Quantifying physical vulnerability in the built environment. J Volcanol Geotherm Res. 2014;276:105-20.
Kandlbauer J, Carey SN, Sparks RSJ. The 1815 Tambora ash fall: implications for transport and deposition of distal ash on land and in the deep sea. Bull Volcanol. 2013;75(4):1-11.

Macedonio G, Costa A. Brief Communication "Rain effect on the load of tephra deposits". Nat Hazards Earth Syst Sci. 2012;12(4):1229-33.

Magill C, Blong R. Volcanic risk ranking for Auckland, New Zealand. II: Hazard consequences and risk calculation. Bull Volcanol. 2005;67(4):340-9.

Magill C, Blong R, McAneney J. VolcaNZ-A volcanic loss model for Auckland, New Zealand. J Volcanol Geotherm Res. 2006;149(3-4):329-45.

Maqsood, T., Wehner, M., Ryu, H., Edwards, M., Dale, K. and Miller, V., 2014. GAR15 Vulnerability Functions. Reporting on the UNISDR/GA SE Asian Regional Workshop on Structural Vulnerability Models for the GAR Global Risk Assessment, 11-14 November, 2013, Geoscience Australia, Canberra, Australia. Record 2014/38, http://dx.doi.org/10.11636/Record.2014.038.

Pomonis A, Spence R, Baxter P. Risk assessment of residential buildings for an eruption of Furnas Volcano, Sao Miguel, the Azores. J Volcanol Geotherm Res. 1999;92(1-2):107-31.

RMS. DLM Reference Guide - Import data, Construction classes and occupancy Types, RMS Supported Countries. California: Risk Management Solutions; 2011.

Rossetto T, lannou I, Grant DN. Existing empirical vulnerability and fragility functions: compendium and guide for selection. Pavia: GEM Technical Report, The GEM Foundation; 2013.

Self S, Rampino MR, Newton MS, Wolff JA. Volcanological study of the great Tambora eruption of 1815. Geology. 1984;12:659-63.

Shipley, S.and Sarna-Wojcicki, A.: (1982) Distribution, thickness, and mass of late Pleistocene and Holocene tephra from major volcanoes in the northwestern United States: a preliminary assessment of hazards from volcanic ejecta to nuclear reactors in the Pacific Northwest. U.S. Geological Survey Miscellaneous Field Studies Map MF-1435

Spence R, Kelman I, Baxter P, Zuccaro G, Petrazzuoli S. Residential building and occupant vulnerability to tephra fall. Nat Hazards Earth Syst Sci. 2005;5:477-94.

Spence, R., Komorowski, J.-C., Saito, K., Brown, A., Pomonis, A., Toyos, G. and Baxter, P., 2008a. Modelling the impact of a hypothetical sub-Plinian eruption at La Soufrière of Guadeloupe (Lesser Antilles). Journal of Volcanology and Geothermal Research, 178(3): 516-528

Spence R, Pomonis A, Baxter P, Coburn A, White M, Dayrit M, Field Epidemiology Training Program Team. Building damage caused by the Mount Pinatubo eruption of June 15, 1991. In: Newhall CG, Punongbayan RS, editors. Fire and Mud: eruptions and lahars of Mount Pinatubo, Philippines. Seattle: Philippines Institute of Volcanology and Seismology, University of Washington Press; 1996. p. 1055-61.

Spence, R., So, E., Jenny, S., Castella, H., Ewald, M. and Booth, E., 2008b. The Global Earthquake Vulnerability Estimation System (GEVES): an approach for earthquake risk assessment for insurance applications. Bulletin of Earthquake Engineering, 6(3): 463-483.

Volcanic Ashfall Impacts Working Group, 2016. Volcanic Ashfall Impacts and Mitigation. Available from: https://volcanoes.usgs.gov/volcanic_ash/. Last accessed: 4 December 2016.

Wilson, T.M., Stewart, C., Sword-Daniels, V., Leonard, G.S., Johnston, D.M., Cole, J.W., Wardman, J., Wilson, G. and Barnard, S.T., 2012. Volcanic ash impacts on critical infrastructure. Physics and Chemistry of the Earth, Parts A/B/C, 45-46: 5-23.

Zuccaro G, Cacace F, Spence RJS, Baxter PJ. Impact of explosive eruption scenarios at Vesuvius. J Volcanol Geotherm Res. 2008;178(3):416-53. 